\title{
RELATIONSHIP BETWEEN OLIVE OIL:AIR, SALINE:AIR, AND RAT BRAIN:AIR PARTITION COEFFICIENTS OF ORGANIC SOLVENTS IN VITRO
}

\author{
Cécil J. W. Meulenberg, Anna G. Wijnker, Henk P. M. Vijverberg \\ Institute for Risk Assessment Sciences (IRAS), Toxicology Division, \\ Utrecht University, Utrecht, the Netherlands
}

\begin{abstract}
Partition coefficients of 28 volatile organic solvents (13 alkylbenzenes, 10 chlorinated hydrocarbons, and 5 ketones) in olive oil, saline, and rat brain tissue homogenates were measured by equilibration in a closed vial and subsequent gas-chromatographic analysis of headspace air. The values of oil and saline partition coefficients correlate well with previously reported data. Brain partition coefficients were fit to a bilinear equation of the form $\mathrm{P}_{\text {brain:air }}=\alpha_{0} \mathrm{P}_{\text {oil:air }}+$ $\alpha_{s} \mathrm{P}_{\text {saline:air }}+c$. The regression coefficients accurately predicted previously reported rat brain partition coefficients of 19 solvents with distinct physicochemical properties within a factor of 2.5. The combined data set of presently determined and previously reported brain partition coefficients $(n=46)$ yields tissue-specific regression coefficients for solvent partitioning in rat brain of 0.028 for $\alpha_{O} 0.845$ for $\alpha_{S}$ and 0.90 for the intercept, with coefficients of variation amounting to $11 \%, 4 \%$, and $463 \%$, respectively. The generalized empirical relationship predicts the brain partition coefficients within a factor of 2.5 accurately for $95 \%$ of the compounds. The ratios of rat brain concentrations calculated from predicted and measured $\mathrm{P}_{\text {brain:air }}$ and $\mathrm{P}_{\text {blood:air }}$ values were within a factor of 4 for $95 \%$ of the compounds. It was concluded that the enlargement of the empirical data set leads to more reliable predictions of rat brain partition coefficients, particularly for the lipophilic volatile organic compounds.
\end{abstract}

Occupational exposure to organic solvents, which constitute a large heterogeneous class of chemicals, may produce adverse, neurotoxic effects (Mikkelsen, 1997; White \& Proctor, 1997). Only a few studies on rodents have addressed the detailed time course of brain concentrations of solvents during inhalation exposure, the most common way of ambient exposure to volatile compounds (Bruckner \& Peterson, 1981; Benignus et al., 1981; Kishi et al., 1988; Warren et al., 1998). Incorporation of these data into physiologically based pharmacokinetic (PBPK) models can provide more detailed information concerning the relationship between exposure and brain chemical concentrations, since PBPK models allow for extrapolation beyond the observed dose range, route, and

Received 6 December 2002; sent for revision 13 January 2003; accepted 25 February 2003.

We thank Drs. Elsa Artola-Garicano, Joop Hermens, and Johannes Tolls for useful discussions and comments, and Paula Martens, Ineke van Holsteijn, and Nicoline Treijtel for providing rat brains. This study was financially supported by the Dutch Platform for Alternatives to Animal Testing (PAD) grant 95-03.

Address correspondence to Henk P. M. Vijverberg, Institute for Risk Assessment Sciences (IRAS), Toxicology Division, Utrecht University, PO Box 80176, NL-3508 TD Utrecht, the Netherlands. E-mail: H.Vijverberg@iras.uu.nl 
species. However, the modeling of a specific brain compartment is hampered by the lack of both brain partition coefficients and in vivo data. The knowledge concerning solvent concentrations in the target tissue during relevant exposure scenarios will contribute to understanding the potential neurotoxicity of solvents.

Partitioning of a compound to a specific tissue depends on the affinities of the specific compound for blood and for the tissue. The partitioning behavior of volatile organic compounds (VOCs) can be studied by the determination of partition coefficients in an in vitro closed vial system (Sato \& Nakajima, 1979a; Gargas et al., 1989). Tissue:air partition coefficients $\left(P_{\text {tissue:air }}\right)$ for VOCs describe the ratio of compound concentration between the tissue and air in the headspace, at equilibrium. Consequently, blood:tissue partition coefficients are defined as the ratio of the blood:air partition coefficient $\left(P_{\text {blood:air }}\right)$ and the tissue:air partition coefficient $\left(P_{\text {tissue:air }}\right)$.

As reviewed by Payne and Kenny (2002), various theoretical models have been developed to predict $P_{\text {tissue:air }}$ of VOCs on the basis of tissue partitioning mechanisms, requiring detailed knowledge of tissue composition (Connell et al., 1993; Poulin \& Krishnan, 1995a, 1995b), or on an empirical basis, assuming that tissues are solely composed of water and lipid (Gargas et al., 1989; DeJongh et al., 1997). Prediction of tissue partitioning on a rational basis not only requires knowledge of the relative fractions of lipids, water, and proteins, which may vary between tissues and species and with age, but also on the relative affinities of the VOCs for the various tissue constituents (Poulin \& Krishnan, 1995a, 1995b). A simplified empirical approach, successfully applied to a set of 12 volatile anesthetics for various human tissues (Droz, 1978), hypothesizes that partitioning of a compound in a specific tissue is determined completely by lipophilic and hydrophilic tissue interactions. More recently, the general applicability of this approach has been tested using the largest possible data sets on VOC partition coefficients in rat and human tissues available from the literature (Meulenberg \& Vijverberg, 2000). The empirical approach showed that $P_{\text {tissue:air }}$ can be described as a linear combination of $P_{\text {saline:air }}$ and $P_{\text {olive oil:air }}$ for large numbers of VOCs $(n=16-109)$ with diverse physicochemical properties. From the data in this study it was concluded that species- and tissue-specific regression coefficients can be used to predict tissue partitioning of VOCs without prior knowledge of tissue composition (Meulenberg \& Vijverberg, 2000). However, inherent to the approach is that the reliability of predictions will depend on the data used to establish the empirical relation. The data set previously used to obtain the regression coefficients for the partitioning of VOCs in rat brain was limited to 19 compounds with a bias toward hydrophilic compounds. Thus, the general applicability of the empirical relation to predict rat brain partition coefficients reliably, and in particular those of lipophilic solvents, remains to be established. Here rat $P_{\text {brain:air }}$ for 27 additional VOCs was measured by the vial equilibration method (Sato \& Nakajima, 1979a). The values are compared with previously published values and bilinear regressions were performed to relate tissue, oil, and saline partition coefficients. 


\section{MATERIAL AND METHODS}

\section{Chemicals and Solutions}

All chemicals used were obtained from commercial suppliers and were of $>95 \%$ purity. Aliquots of chemical $(5-20 \mu \mathrm{l})$ were added to a large volume $(25 \mathrm{ml})$ of distilled water followed by overnight (or sometimes a few days) stirring in a tightly closed glass bottle at room temperature. Olive oil (highly refined, low acidity) was obtained from Sigma, St. Louis, $\mathrm{MO}$, and phosphate-buffered saline (PBS; $154 \mathrm{mM} \mathrm{NaCl}, 1.5 \mathrm{mM} \mathrm{KH} \mathrm{PO}_{4}, 2.7 \mathrm{mM} \mathrm{Na}{ }_{2} \mathrm{HPO}_{4} \cdot 7 \mathrm{H}_{2} \mathrm{O} ; \mathrm{pH}$ 7.2) from Gibco, Gaithersburg, MD.

\section{Tissue Homogenate}

Whole brains were obtained from young adult male Wistar rats $(\mathrm{U}: \mathrm{Wu}$; 200-350 g), which had been sacrificed by decapitation for donation of liver or kidney tissue for other experimental projects. Brains were rinsed with sterile PBS, frozen, and stored at $-20^{\circ} \mathrm{C}$ until further use. Freshly thawed brain tissue and sterile PBS at a 1:3 or, where applicable, a 1:2 wet weight brain:saline volume ratio (assuming a tissue density of $1.0 \mathrm{~g} / \mathrm{ml}$ ) were homogenized for 3 min at 700 rpm (Potter S, Braun).

\section{Partition Coefficients}

Experimental procedures were generally as described by Sato and Nakajima (1979a). In short, glass vials (Supelco, Inc., Bellefonte, PA) with an average volume of $17.2 \pm 0.1 \mathrm{ml}$ were each filled with $100 \mu \mathrm{l}$ of stock solution of the chemical in distilled water (reference vials). For test vials, olive oil (50 or $100 \mu \mathrm{l})$, PBS $(0.5$ or $5 \mathrm{ml})$, or brain tissue homogenate $(0.5 \mathrm{ml})$ was added. The vials were closed with plastic screw caps containing a Teflon-coated rubber septum to provide an airtight seal while the gas phase remained readily accessible. A thermoregulated water bath was used to shake and incubate the vials at $37^{\circ} \mathrm{C}$. It was ensured that at the time of headspace air analysis, equilibrium was reached for the partitioning of both lipophilic and hydrophilic compounds. The headspace air of the vials containing olive oil and saline was routinely sampled at $24 \mathrm{~h}$ and brain homogenate-containing vials were sampled at 4 or $8 \mathrm{~h}$ of incubation. Concentrations were measured in 1-ml samples of headspace air withdrawn from each vial. The samples were analyzed by gas chromatography (Carlo Erba, model HRGC 5300, Carlo Erba Instruments, Milan, Italy) utilizing a flame ionization detector and where applicable an electron-capture detector on a $15 \mathrm{~m} \times 0.32 \mathrm{~mm}$ DB-1 column (J \& W Scientific, Folson, CA) with $0.25 \mu \mathrm{m}$ film thickness and $\mathrm{He}$ as carrier gas. In general, the oven was kept isothermic at 40 or $90^{\circ} \mathrm{C}$. The injector temperature was $225^{\circ} \mathrm{C}$ and the detector temperature was $325^{\circ} \mathrm{C}$. The solvent concentration was proportional to the height of the obtained peaks. $P_{\text {oillair }}$ and $P_{\text {saline:air }}$ were calculated from the measured peak heights using Eqs. (5) and (6) of Sato and Nakajima (1979a). For calculation of

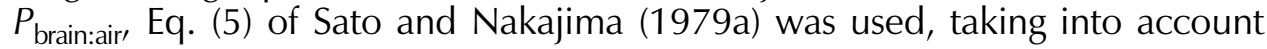


the amount of PBS contained by the tissue homogenate. Values of partition coefficients are reported as the mean of three to five independent measurements with their standard deviation (SD).

\section{Regression Analysis}

$P_{\text {brain:air }}$ is described as a bilinear function of $P_{\text {olive oilair }}$ and $P_{\text {saline:air }}$ according to Meulenberg \& Vijverberg, 2000:

$$
P_{\text {brain:air }}=\alpha_{\mathrm{o}} P_{\text {oil:air }}+\alpha_{\mathrm{s}} P_{\text {saline:air }}+C
$$

The coefficients $\alpha_{\mathrm{O}}$ and $\alpha_{\mathrm{S}}$ in Eq. (1) represent the tissue-specific contributions of the lipophilic and hydrophilic interactions to the solubility of the compounds in brain. Tissue partitioning was fitted using weighted bilinear regression. Dividing each brain partition coefficient by its measured value, using the SPSS weight estimation procedure, optimized the regression. The performed weighting results in equal relative weights of individual compounds in the regressions, such that the regressions resulted in equal relative errors for both small and large $P_{\text {brain:air }}$ Estimated values of the regression coefficients $\alpha_{0}$ and $\alpha_{\mathrm{s}}$ and of the constant $c$ are reported with their coefficients of variation $(\mathrm{CV}, \%)$, and regressions are presented with their correlation coefficients $\left(R^{2}\right)$. Cross-correlation between fitted parameters was also monitored to judge the quality of the regressions and possible redundancy of parameters. All regression analyses were performed using SigmaPlot 3.02 software (Jandel Scientific Software, SPSS, Inc., Chicago). To judge the applicability of the estimated regression coefficients for the prediction of tissue partition coefficients, the residuals of fitted and experimentally determined values were analyzed. The 2.5-th and 97.5-th percentiles of the ratios of the partition coefficients predicted by the bilinear regression and of the measured values of the partition coefficients were calculated and the resulting 95\% confidence range is indicated in the results. In order to further assess the reliability of the results, $P_{\text {brain:blood }}$ (the quotient of $P_{\text {brain:air }}$ and $P_{\text {blood:air }}$ ) values were calculated from predicted partition coefficients and from measured partition coefficients. Predicted and measured $P_{\text {blood:air }}$ values were obtained from Meulenberg and Vijverberg (2000). For each compound the ratio of predicted $P_{\text {brain:blood }}$ and experimental $P_{\text {brain:blood }}$ reflects the ratio of predicted and experimental steadystate brain concentration.

\section{Statistical Analysis}

The mean ratios from various sources were compared with the two-tailed paired Student's $t$-test in which the significance level was set at $p=.05$. The distribution of the residuals was tested for normality using the KolmogorovSmirnov test in which the level of significance was set at $p=.05$. 


\section{RESULTS}

\section{Partition Coefficients of Organic Solvents}

Partition coefficients were determined for three distinct chemical classes of volatile organic solvents (Table 1): alkylbenzenes $(n=13)$, aliphatic chlorinated hydrocarbons $(n=10)$, and ketones $(n=5)$. Initially, experiments were performed to establish that equilibrium between headspace air and test substances in the vials was reached for all of the compounds. Toward this goal the headspace air concentration of several of the more lipophilic and more hydrophilic compounds was measured at various intervals after incubation for up to $24 \mathrm{~h}$. These experiments showed that equilibrium between the samples and the headspace air was generally reached within 4-6h of incubation. Apart from the use of sterile PBS to rinse excised brains and to prepare brain homogenates, no specific measures were taken to prevent degradation of tissue or solvent during

TABLE 1. Saline:Air, Rat Brain:Air, and Olive Oil:Air Partition Coefficients of Organic Solvents at $37^{\circ} \mathrm{C}$

\begin{tabular}{|c|c|c|c|c|}
\hline & Compound & $P_{\text {saline:air }}$ & $P_{\text {brain:air }}$ & $P_{\text {olive oil:air }}$ \\
\hline 1 & Benzene & $2.80 \pm 0.15$ & $25.8 \pm 4.39$ & $480 \pm 36.0$ \\
\hline 2 & Toluene & $2.28 \pm 0.61$ & $41.8 \pm 6.02$ & $1198 \pm 285$ \\
\hline 3 & o-Xylene & $4.92 \pm 0.60$ & $110 \pm 16.2$ & $3711 \pm 284$ \\
\hline 4 & $m$-Xylene & $1.61 \pm 0.17$ & $71.9 \pm 14.2$ & $3336 \pm 280$ \\
\hline 5 & p-Xylene & $1.61 \pm 0.16$ & $92.1 \pm 11.0$ & $2914 \pm 142$ \\
\hline 6 & Ethylbenzene & $1.71 \pm 0.15$ & $79.2 \pm 7.84$ & $3520 \pm 324$ \\
\hline 7 & Styrene & $3.71 \pm 0.21$ & $111 \pm 10.2$ & $3596 \pm 187$ \\
\hline 8 & Propylbenzene & $1.92 \pm 0.52$ & $142 \pm 8.75$ & $6054 \pm 593$ \\
\hline 9 & Allylbenzene & $1.94 \pm 0.25$ & $134 \pm 14.4$ & $4384 \pm 421$ \\
\hline 10 & Isopropylbenzene & $0.80 \pm 0.08$ & $86.4 \pm 11.8$ & $3674 \pm 198$ \\
\hline 11 & 1,3,5-Trimethylbenzene & $1.63 \pm 0.25$ & $160 \pm 27.3$ & $6752 \pm 297$ \\
\hline 12 & 1,2,4-Trimethylbenzene & $2.00 \pm 0.16$ & $224 \pm 43.2$ & $7864 \pm 991$ \\
\hline 13 & 1,2,3-Trimethylbenzene & $1.49 \pm 0.22$ & $246 \pm 74.2$ & $9263 \pm 769$ \\
\hline $14^{a}$ & 1,1-Dichloroethane & $1.60 \pm 0.18$ & 6.29 & $144 \pm 18.3$ \\
\hline 15 & 1,2-Dichloroethane & $9.37 \pm 2.53$ & $22.0 \pm 8.65$ & $413 \pm 16.1$ \\
\hline 16 & 1,1,1-Trichloroethane & $0.81 \pm 0.19$ & $13.3 \pm 5.98$ & $268 \pm 14.5$ \\
\hline 17 & 1,1,2-Trichloroethane & $13.1 \pm 0.28$ & $46.0 \pm 4.87$ & $1604 \pm 11.2$ \\
\hline 18 & 1,1,1,2-Tetrachloroethane & $4.58 \pm 0.16$ & $90.0 \pm 7.65$ & $2853 \pm 97.0$ \\
\hline 19 & 1,1,2,2-Tetrachloroethane & $35.6 \pm 6.05$ & $344 \pm 21.0$ & $10,125 \pm 547$ \\
\hline 20 & trans-1,2-Dichloroethylene & $1.18 \pm 0.24$ & $10.4 \pm 5.58$ & $117 \pm 23.4$ \\
\hline 21 & cis-1,2-Dichloroethylene & $2.53 \pm 0.21$ & $16.0 \pm 10.5$ & $106 \pm 10.5$ \\
\hline 22 & Trichloroethylene & $0.95 \pm 0.19$ & $4.63 \pm 1.74$ & $421 \pm 36.2$ \\
\hline 23 & Tetrachloroethylene & $0.74 \pm 0.13$ & $44.5 \pm 12.7$ & $1327 \pm 61.0$ \\
\hline 24 & Acetone & $203 \pm 12.8$ & $200 \pm 46.5$ & $31.0 \pm 4.18$ \\
\hline 25 & 2-Butanone & $122 \pm 27.5$ & $119 \pm 95.4$ & $93.2 \pm 7.27$ \\
\hline 26 & 2-Pentanone & $49.2 \pm 2.51$ & $123 \pm 14.0$ & $255 \pm 40.0$ \\
\hline 27 & 2-Hexanone & $66.8 \pm 12.2$ & $89.4 \pm 12.4$ & $548 \pm 27.9$ \\
\hline 28 & 3-Pentanone & $77.8 \pm 11.8$ & $39.6 \pm 17.1$ & $266 \pm 15.7$ \\
\hline
\end{tabular}

Note. Values are means $\pm \mathrm{SD}$, with $n=3-5$.

${ }^{a}$ The $P_{\text {brain:air }}$ for this compound could not be determined; consequently, it was not used in the bilinear regressions, and this value for $P_{\text {brain:air }}$ represents a predicted value only. 
incubation. However, the stable height of the peaks detected from the headspace of vials containing brain homogenate at various times between 4 and $24 \mathrm{~h}$ of incubation (not shown) indicated that any conversions occurring would be too slow or too small to affect the results. In subsequent experiments, oil and saline partition coefficients were routinely determined after $24 \mathrm{~h}$ of incubation and brain partition coefficients after $4 \mathrm{~h}$ of incubation.

Saline partition coefficients for the 28 VOCs investigated ranged between 0.74 and 203 and oil partition coefficients between 31 and 10,125 (Table 1). The physicochemical properties of the compounds are graphically illustrated in Figure 1. The scatter plot shows that the properties of the compounds investigated here only partially overlap with those of 19 VOCs for which brain partition coefficients were previously reported in the literature (Fassoulaki \& Eger, 1986; Kaneko et al., 1994).

The values of oil and saline partition coefficients for the organic solvents previously determined in two separate studies (Sato \& Nakajima 1979a, 1979b; Gargas et al., 1989) and the presently measured values are compared in Figure 2. Values for $P_{\text {water:air }}$ reported by Sato and Nakajima (1979a, 1979b) and for $P_{\text {saline:air }}$ reported by Gargas et al. (1989) (Figure $2 A$ ) plotted against the present results are close to the unity line. The mean ratio of values previously

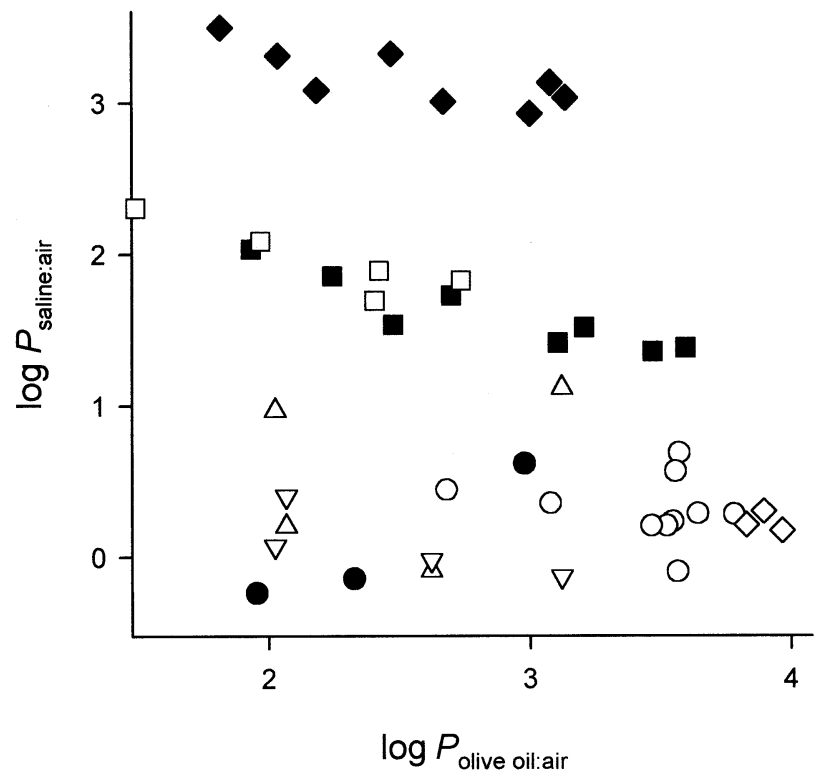

FIGURE 1. Scatter plot of $\log P_{\text {oilair }}$ vs. $\log P_{\text {saline:air }}$ for the compounds used in this study. The compounds for which partition coefficients are currently determined $(n=28)$ are indicated by open symbols $(\bigcirc$ monoand dialkylbenzenes, $n=10$; $\diamond$ trimethylbenzenes, $n=3 ; \triangle$ chloroethanes, $n=6$; $\nabla$ chloroethylenes, $n=4$; $\square$ ketones, $n=5$ ). Values for 19 additional compounds, for which rat $P_{\text {brain:air }}$ was previously determined, are indicated by closed symbols ( haloalkanes, $n=3$, Fassoulaki \& Eger, 1986; $\boldsymbol{\sim}$ alcohols, $n=8$, and $\mathbf{\square}$ acetate esters, $n=8$, Kaneko et al., 1994). 

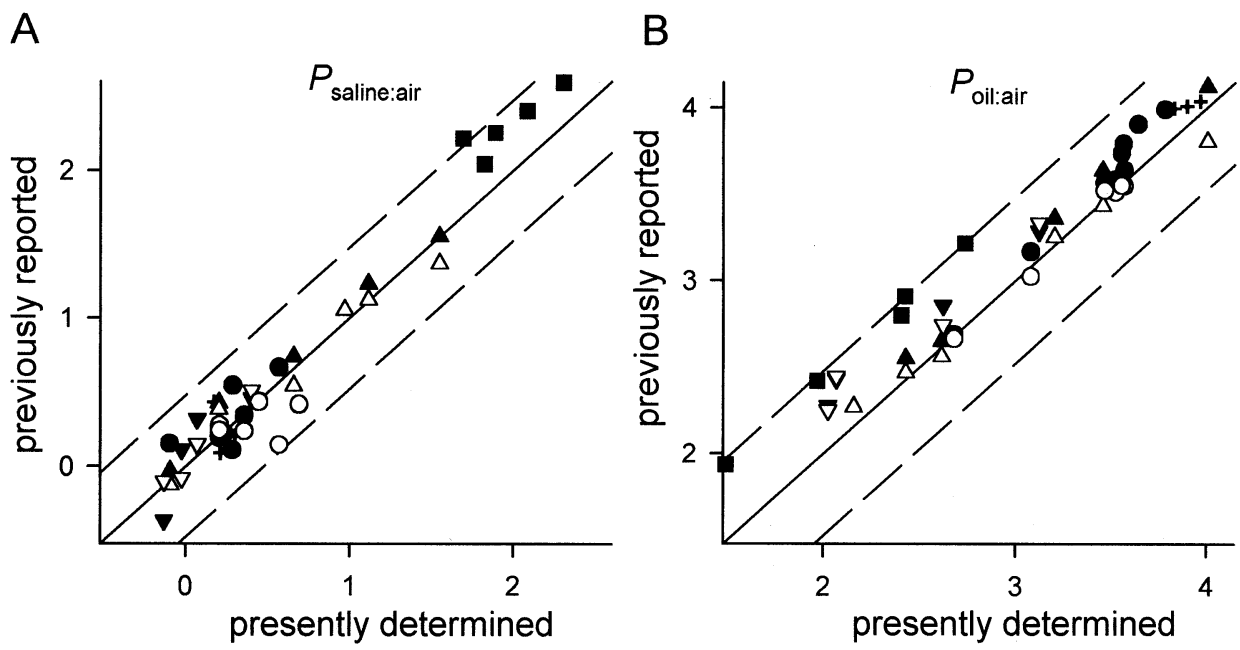

FIGURE 2. Comparison of currently determined liquid:air partition coefficients with previously reported (A) $P_{\text {saline:air }}$ or $P_{\text {water:air }}$ and (B) $P_{\text {oil:air }}$ values. The $P_{\text {saline:air }}$ and $P_{\text {oil:air }}$ are compared with values for $P_{\text {water:air }}$ and $P_{\text {oilair }}$ reported by Sato and Nakajima (1979a, 1979b) $\left(n=25\right.$; closed symbols, both with $\left.R^{2}=98\right)$, and with $P_{\text {saline:air }}$ and $P_{\text {oil:air }}$ reported by Gargas et al. (1989) $\left(n=16\right.$; open symbols, $R^{2}=.96$ and .95 , respectively). Different symbols are used to identify different classes of compounds $(O,-$ mono- and dialkylbenzenes; $\triangle, \boldsymbol{\Delta}$ chloroethanes; $\nabla, \boldsymbol{\nabla}$ chloroethylenes; $\mathbf{\square}$ ketones). Reported partition coefficients of the trimethylbenzenes (Järnberg \& Johanson, 1995) are also indicated $(n=3,+)$. The solid lines represent the identity lines with a slope of 1 , and the dashed lines indicate deviations from unity by a factor 3 .

reported by Gargas et al. (1989) and presently measured values amounts to $0.97 \pm 0.30$ (not significantly different). The mean ratio of $P_{\text {water:air }}$ reported by Sato and Nakajima (1979a, 1979b) and the present results amount to 1.40 \pm 0.62 , which is a significant deviation from 1 . Despite the difference with the data set of Sato and Nakajima (1979a, 1979b), maximum deviations from unity for the experimentally determined $P_{\text {saline:air }}$ and previously reported partition coefficients, including those reported for the trimethylbenzenes (Järnberg \& Johanson, 1995), are within a factor of 3 (dashed lines in Figure 2A). The comparison for the olive oil:air partition coefficients (Figure 2B) yields a similar picture. The mean ratio of $P_{\text {oil:air }}$ reported by Gargas et al. (1989) and the presently measured $P_{\text {oil:air }}$ amounts to $0.83 \pm 0.16$, demonstrating no significant difference. However, the experimentally determined $P_{\text {oilair }}$ appear to deviate significantly from data reported by Sato and Nakajima (1979a, 1979b), with a mean ratio amounting to $1.71 \pm 0.64$. Maximum deviations from unity for the experimentally determined $P_{\text {oil:air }}$ and previously reported partition coefficients, including those reported for the trimethylbenzenes (Järnberg \& Johanson, 1995), are within a factor of 3 (dashed lines in Figure 2B). The comparisons show that the values of the saline:air and oil:air partition coefficients determined here are slightly lower than those reported by Sato and Nakajima (1979a, 1979b) and are equal to or slightly higher than reported by Gargas et al. (1989). All these studies were conducted with a similar methodology (Sato \& Nakajima, 1979a). 
Brain partition coefficients were determined after $4 \mathrm{~h}$ of incubation, and the mean values of $P_{\text {brain:air }}$ and standard deviations are listed in Table 1 . In general, standard deviations were $<30 \%$ of the mean, comparable with the variation in partition coefficients reported by Sato and Nakajima (1979a, 1979b). For some chlorinated compounds with values of $P_{\text {saline:air }}$ close to 1 and corresponding $P_{\text {oil:air }}<2000$, that is, compounds 14, 16, and 20-23 in Table 1, it was noticed that after $4 \mathrm{~h}$ of incubation with brain homogenate, $>95 \%$ was still present in the headspace of the vial. For these compounds additional measurements were performed on a more concentrated brain homogenate and after $8 \mathrm{~h}$ of incubation. Only for trichloroethylene and tetrachloroethylene (compounds 22 and 23) the difference between the peaks from the tissue-containing and reference vials increased to $>5 \%$ and more reliable values of $P_{\text {brain:air }}$ were obtained. For the remaining chlorinated compounds there was an increase of the interference between the gas chromatographic peak of the compound and the peak of the brain homogenate. As a consequence, $P_{\text {brain:air }}$ values for compounds 16, 20, and 21 represent the less reliable values obtained after $4 \mathrm{~h}$ of incubation, and $P_{\text {brain:air }}$ for 1,1-dichloroethane (compound 14) could not be determined experimentally (consequently it is not used in the following bilinear regressions). All partition coefficients are presented in Table $1(n=28)$.

\section{Predicting Rat Brain Partitioning of VOCs}

Prediction of the rat brain partition coefficients of VOCs should be possible on the basis of a previously established bilinear relation between tissue, oil, and saline partition coefficients for 19 VOCs (Meulenberg \& Vijverberg, 2000). The results of this prediction are shown in a residual plot (Figure 3A). The mean ratio between predicted and experimental $P_{\text {brain:air, }}$ amounting to $1.73 \pm 0.90$, is significantly deviating from unity and the residuals are distributed normally around the mean. The minimum and maximum of the ratios are 0.42 and 5.08. From Figure $3 \mathrm{~A}$ it appears that the partition coefficients of the more lipophilic VOCs are overpredicted by the previously calculated regression coefficients. This may be caused by the relative underrepresentation of lipophilic VOCs in the literature data set available at the time, resulting in an inaccurate regression coefficient $\alpha_{0}$ (Meulenberg \& Vijverberg, 2000).

Conversely, it should be possible to predict the previously reported $P_{\text {brain:air }}$ on the basis of the novel data presented in Table 1. A bilinear regression according to Eq. (1) on the data in Table 1, with the exception of compound 14 , yielded values of the regression coefficients of $0.026 \pm 7 \%$ (fitted value $\pm C V)$ for $\alpha_{\mathrm{O}^{\prime}} 0.879 \pm 12 \%$ for $\alpha_{s^{\prime}}$ and $1.37 \pm 253 \%$ for $c(n=27)$. Using these regression coefficients to predict previously reported values of $P_{\text {brain:air }}$ of VOCs yielded a mean ratio between predicted and experimental $P_{\text {brain:air }}$ amounting to $0.98 \pm 0.47$ (Figure $3 \mathrm{~B}$ ). The minimum and maximum of the ratios are 0.42 and 2.07 . The residuals are distributed normally around the mean. The cross-comparison suggests that the current data set, composed of 

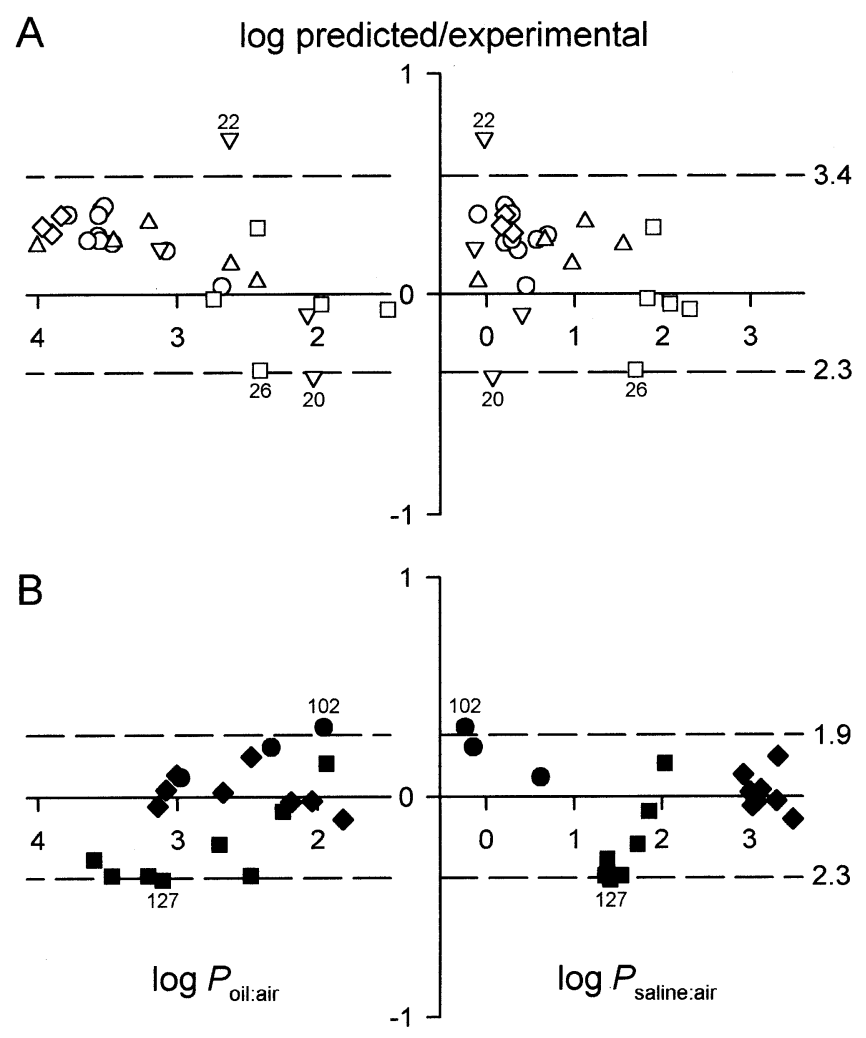

FIGURE 3. Cross-predictions of rat brain:air partition coefficients. Double-logarithmic representation of the quotient of predicted and experimentally determined rat $P_{\text {brain:air }}$ against $P_{\text {oilair }}$ and $P_{\text {saline:air }}$ (A) Predictions of the presently determined $P_{\text {brain:air }}$ from $P_{\text {oil:air }}$ and $P_{\text {saline:air }}$ (see Table 1 ) by the regression coefficients for rat brain partitioning obtained from previously reported literature values (Meulenberg \& Vijverberg, 2000). Outliers are identified by their compound number according to Table 1. (B) Predictions of $P_{\text {brain:air }}$ values previously reported in the literature by the regression coefficients obtained from fitting Eq. (1) to the present experimental data. Outliers isoflurane (102) and isobutyl acetate (127) are identified by the numbering according to Table 1 of Meulenberg and Vijverberg (2000). The 2.5-th and 97.5-th percentiles are drawn (dashed lines) and the values of the percentiles are indicated at the right. Different symbols are used to identify different classes of compounds as in Figure 1.

27 VOCs, provides more accurate predictions than the previously used data set, composed of 19 VOCs.

Since the larger data set provides the more reliable predictions the two data sets were merged to generate a set of VOCs with a wider range of physicochemical properties (see Figure $1 ; n=46$ ). The values for 27 VOCs from Table 1 and the literature values for 19 VOCs (see Table 1 in Meulenberg \& Vijverberg, 2000) were used to relate $P_{\text {brain:air }}$ to $P_{\text {oil:air }}$ and $P_{\text {saline:air }}$ in a bilinear regression according to Eq. (1). The regression plane obtained by fitting Eq. (1) to the combined set of data is plotted in a three-dimensional graph in Figure 4A. The slope of the plane describing brain partitioning is mainly determined by $\alpha_{s}$. 


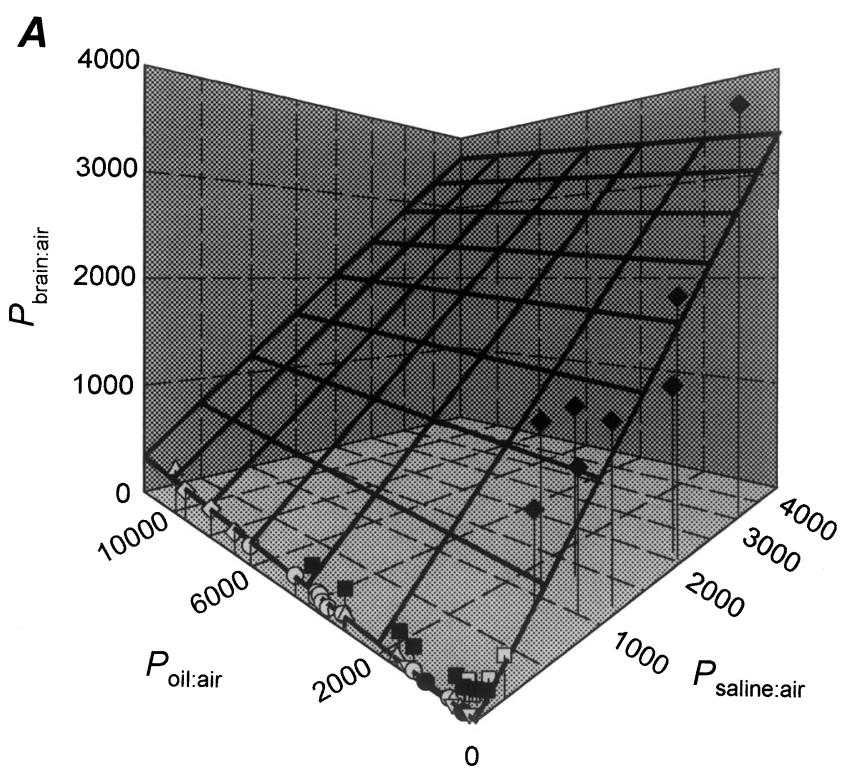

B<smiles></smiles>

\section{log predicted/experimental}

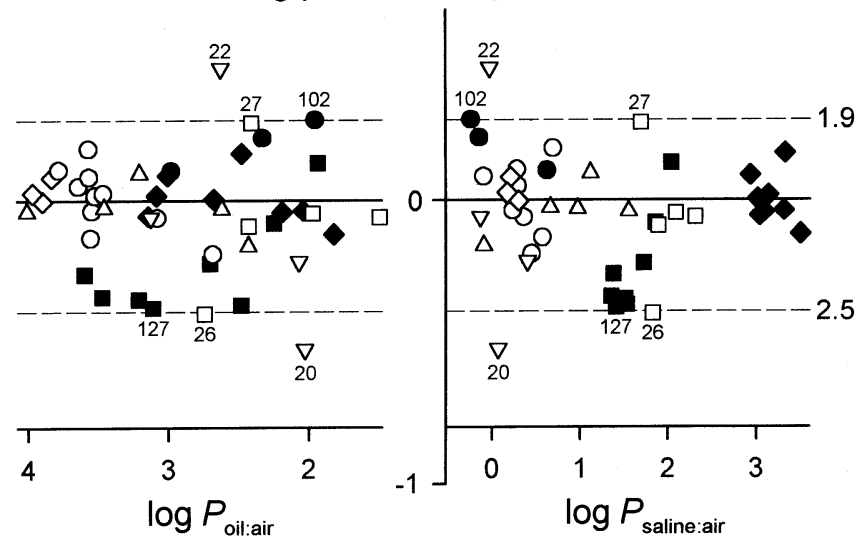

FIGURE 4. Results of the bilinear regression on the data set composed of the presently determined and previously reported partition coefficients. (A) Three-dimensional representation of the bilinear regression between $P_{\text {oil:air }} P_{\text {saline:air, }}$ and rat $P_{\text {brain:air }}$ according to Eq. (1). The orientation of the plane is determined by the regression coefficients $\alpha_{\mathrm{O}}(0.028 \pm 11 \%)$ and $\alpha_{\mathrm{s}}(0.845 \pm 4 \%)$. The estimated intercept $c$ amounts to $0.90 \pm 463 \%$ (fitted value $\pm \mathrm{CV}$ ). Note that the regression of rat $P_{\text {brain:air }}$ depends more steeply on $P_{\text {saline:air }}$. The solid grid represents the fitted plane of rat brain partition coefficients. The grid in the fitted plane and the dashed grid in the horizontal plane are identically spaced. Vertical lines are drawn from the horizontal plane to indicate the position of the data points. (B) Double-logarithmic representation of the quotient of fitted and experimentally determined $P_{\text {brain:air }}$ against $P_{\text {oilair }}$ and against $P_{\text {saline:air }}$ Results are presented in two dimensions for a clear insight into the distribution of all points relative to the fitted regression plane. The 2.5-th and 97.5-th percentiles are drawn (dashed lines) and the values of the percentiles are indicated at the right. The closed symbols $(n=19)$ represent experimental rat $P_{\text {brain:air }}$ values as previously compiled (Meulenberg \& Vijverberg, 2000) and the open symbols

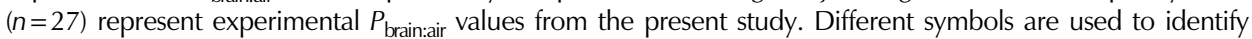
different classes of compounds as in Figure 1. Outliers are identified by their compound number. 
The result of the regression on the combined set gives estimates for $\alpha_{0}$ of $0.028 \pm 11 \%$ (fitted value $\pm C V$ ), for $\alpha_{s} 0.845 \pm 4 \%$, and for the intercept $c$ $0.90 \pm 463 \%$. The cross-correlation between the fitted parameters $\alpha_{\mathrm{o}}$ and $\alpha_{\mathrm{s}}$ was 0.003 , and the quality of the regression $\left(R^{2}=.92\right)$ is comparable with previous regression results for rat tissues (Meulenberg \& Vijverberg, 2000).

The equation fitted to brain partitioning of VOCs has been internally validated from plots of the ratio of predicted and observed values. Figure $4 \mathrm{~B}$ is a residual plot of the ratios of $P_{\text {brain:air }}$ predicted by the fitted bilinear equation and experimentally determined $P_{\text {brain:air }}$ values. The residuals are distributed normally around the mean of 1.0 . The minimum and maximum ratios are 0.30 and 2.9. In order to assess the reliability of the values predicted by the bilinear regression, the 2.5-th and 97.5-th percentiles of the ratios of the predicted and experimentally determined partition coefficients were calculated. The resulting 95\% confidence range (0.40-1.9; indicated in Figure 4B) shows that brain partition coefficients are predicted with an accuracy within a factor of 2.5 for $95 \%$ of the VOCs.

\section{DISCUSSION}

The present values of $P_{\text {oil:air }}$ and $P_{\text {saline:air }}$ cannot be distinguished from those reported by Gargas et al. (1989), and are systematically lower than the values reported by Sato and Nakajima (1979a, 1979b). An explanation for the deviation of saline partition coefficients is that Sato and Nakajima (1979a, 1979b) measured partitioning in water, whereas PBS was used in the present study, which is very similar to the $0.9 \% \mathrm{NaCl}$ solution used by Gargas et al. (1989). For volatile anesthetics it was previously noticed that $P_{\text {saline:air }}$ deviates from $P_{\text {water:air }}$ by a factor of $0.87-0.97$, because of the presence of ions, which decreases the maximum water solubility (Steward et al., 1973; Renzi \& Waud, 1977; Halliday et al., 1977; Lerman et al., 1983). If a similar factor would apply to organic solvents in general, this would account for part of the difference found. However, for the $P_{\text {oil:air }}$ a similar picture emerged (Figure 2B). The main difference from the method of Sato and Nakajima (1979a) is the longer incubation period (4-8 $\mathrm{h}$ as compared to $0.5-2 \mathrm{~h}$ ) of the samples. Gargas et al. (1989) also incubated samples for longer periods (1-4 h) than Sato and Nakajima (1979a, 1979b). The present results confirm previously reported differences in partition coefficients of ortho-, meta-, and para-substituted trimethylbenzene (Järnberg \& Johanson, 1995) and xylene (Sato \& Nakajima, 1979a; Gargas et al., 1989). The values of $P_{\text {oilair }}$ and $P_{\text {brain:air }}$ in Table 1 show the same order of ortho $>$ meta $>$ para. However, due to the limited water solubilities of the trimethylbenzenes and the xylenes, this is less clear for the $P_{\text {saline:air }}$ values.

Fitting the bilinear Eq. (1) to the experimental data yielded regression coefficients, which can be used to predict previously reported values of rat brain partition coefficients for 3 haloalkanes (Fassoulaki \& Eger, 1986), and 8 alcohols and 8 acetate esters (Kaneko et al., 1994), that is, the 19 values compiled in Table 1 of Meulenberg and Vijverberg (2000). Figure 3 shows that 
this prediction is accurate within a factor of 2.3 and also shows that the reverse operation, predicting the presently measured values on the basis of regression coefficients determined from the previously reported literature values (Meulenberg \& Vijverberg, 2000), is less accurate. Figure 3A shows that the predicted values of the partition coefficients of the less hydrophilic compounds show the largest deviations. This is due to the difference in hydrophilicity of compounds in the two data sets (see Figures 1 and 3). The relatively high water solubility of compounds for which $P_{\text {brain:air }}$ values were previously reported does not allow for an accurate determination of $\alpha_{\mathrm{O}^{\prime}}$ and the estimated values for this parameter differ considerably between the two data sets. Conversely, the values of $\alpha_{s}$ estimated from the two data sets are equal within experimental error. Both the mechanistic approach (Poulin \& Krishnan, 1995a, 1995b) and the empirical approach (Meulenberg \& Vijverberg, 2000) indicate that the magnitude of VOC tissue partitioning in most organs is mainly determined by the solubility in water. Thus, many compounds will partition mainly into the water fraction of brain tissue, since $\alpha_{\mathrm{s}}>>\alpha_{\mathrm{o}}$. However, for the more lipophilic compounds with a quotient of $P_{\text {oil:air }} / P_{\text {saline:air }}>>\alpha_{\mathrm{s}} / \alpha_{\mathrm{O}^{\prime}}(\sim 30$ for rat brain $)$ the partitioning in lipids will contribute the major part of the total amount of the VOC present in the tissue under steady-state conditions. In this respect it is remarkable that $P_{\text {blood:air }}$ has been reported to decrease when the VOC concentration was increased, while the partitioning into an octanol-water mixture was unaffected with increasing VOC concentration (Béliveau \& Krishnan, 2000). This phenomenon was attributed to the binding of the VOCs to proteins present in the blood. However, protein binding would contribute a saturable component of tissue partitioning only at concentrations of VOCs close to their binding affinity constants, which are in the millimolar range (Poulin \& Krishnan, 1996; Béliveau \& Krishnan, 2000). At lower concentrations the partitioning of VOCs in the water compartment will generally contribute the major part of the total amount in blood, as for rat blood the ratio $\alpha_{\mathrm{S}} / \alpha_{\mathrm{O}} \approx 170$ (Meulenberg \& Vijverberg, 2000), which is 6 times higher than for brain tissue.

Residual analysis of the improved regression for rat brain (Figure 4B) showed that the 95\% confidence range for the ratio of fitted and experimentally determined $P_{\text {brain:air }}$ is within a factor of 2.5. This indicates that the improved equation can predict both previously reported $P_{\text {brain:air }}$ of more hydrophilic compounds and, with equal accuracy, the newly determined $P_{\text {brain:air }}$ of less hydrophilic organic solvents. Thus, the present extension of the data set on rat brain partition coefficients does not improve the accuracy of the predictions made by the model. However, the predictions are more reliable, since they are based on empirical data obtained from a larger number of VOCs with a wider range of physicochemical properties. Using previously reported and predicted $P_{\text {blood:air }}$ (Meulenberg \& Vijverberg, 2000) the ratio of predicted and experimental rat brain concentrations was calculated from $P_{\text {brain:blood }}$ values for 38 of the 46 compounds investigated, since experimental

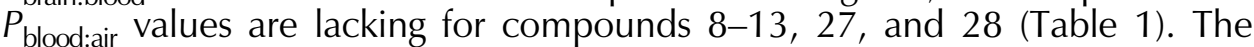
results showed that the model, Eq. (1), predicts the rat brain concentration of 
the 38 VOCs with 95\% confidence limits of $0.43-4.1$; that is, with an accuracy comparable to that obtained in our previous study. Methanol (compound 113 of Meulenberg \& Vijverberg, 2000, with a ratio of 0.35 ) and trichloroethylene (compound 22 with a ratio of 14.8 ) belong to the group of $5 \%$ of the compounds that fall outside the confidence range.

The combined empirical data set, composed of the presently determined and previously reported $P_{\text {brain:air }}$ values, covers a large range of hydrophilic and hydrophobic compounds. Based on this large data set, reliable predictions should be possible. The accuracy of the estimated values of the regression coefficients $\alpha_{\mathrm{O}}$ and $\alpha_{\mathrm{S}}$ is improved and the coefficients of variation now favorably compare with those of the regression coefficients for other tissues for which large data sets were available (Meulenberg \& Vijverberg, 2000).

\section{REFERENCES}

Béliveau, M., and Krishnan, K. 2000. Concentration dependency of rat blood:air partition coefficients of some volatile organic chemicals. J. Toxicol. Environ. Health A 60:377-389.

Benignus, V. A., Muller, K. E., Barton, C. N., and Bittikofer, J. A. 1981. Toluene levels in blood and brain of rats during and after respiratory exposure. Toxicol. Appl. Pharmacol. 61:326-334.

Bruckner, J. V., and Peterson, R. G. 1981. Evaluation of toluene and acetone inhalant abuse: I. Pharmacology and pharmacodynamics. Toxicol. Appl. Pharmacol. 61:27-38.

Connell, D. W., Braddock, R. D., and Mani, S. V. 1993. Prediction of the partition coefficient of lipophilic compounds in the air-mammal tissue system. Sci. Total Environ. Suppl. Pt 2:1383-1396.

Dejongh, J., Verhaar, H. J. M., and Hermens, J. L. M. 1997. A quantitative property-property relationship (QPPR) approach to estimate in vitro tissue-blood partition coefficients of organic chemicals in rats and humans. Arch. Toxicol. 72:17-25.

Droz, P. O. 1978. Contribution à la recherche d'indices biologiques d'exposition aux solvants. Détermination de leurs coefficients de partage et étude de leur comportement dans l'organisme à l'aide de modèles de simulation. Thesis. Neuchâtel University, Switzerland.

Fassoulaki, A., and Eger, E. I. II. 1986. Starvation increases the solubility of volatile anaesthetics in rat liver. Br. J. Anaesth. 58:327-329.

Gargas, M. L., Burgess, R. J., Voisard, D. E., Cason, G. H., and Andersen, M. E. 1989. Partition coefficients of low-molecular weight volatile chemicals in various liquids and tissues. Toxicol. Appl. Pharmacol. 98:87-99.

Halliday, M. M., MacDonald, I., and MacGregor, M. H. G. 1977. Gas chromatographic determination of Ostwald solubility coefficients for cyclopropane, halothane and trichloroethene (trichloroethylene). $\mathrm{Br}$. J. Anaesth. 49:413-417.

Järnberg, J., and Johanson, G. 1995. Liquid/air partition coefficients of the trimethylbenzenes. Toxicol. Ind. Health 11:81-88.

Kaneko, T., Wang, P. Y., and Sato, A. 1994. Partition coefficients of some acetate esters and alcohols in water, blood, olive oil and tissues. Occup. Environ. Med. 51:68-72.

Kishi, R., Harabuschi, I., Ikeda, T., Yokota, H., and Miyake, H. 1988. Neurobehavioral effects and pharmacokinetics of toluene in rats and their relevance to man. Br. J. Ind. Med. 45:396-408.

Lerman, J., Willis, M. M., Gregory, G. A., and Eger, E. I. II 1983. Osmolarity determines the solubility of anesthetics in aqueous solutions at $37^{\circ} \mathrm{C}$. Anesthesiology 59:554-558.

Meulenberg, C. J. W., and Vijverberg, H. P. M. 2000. Empirical relations predicting human and rat tissue:air partition coefficients of volatile organic compounds. Toxicol. Appl. Pharmacol. 165:206-216.

Mikkelsen, S. 1997. Epidemiological update on solvent neurotoxicity. Environ. Res. 73:101-112.

Payne, M. P., and Kenny, L. C. 2002. Comparison of models for the estimation of biological partition coefficients. J. Toxicol. Environ. Health A 65:897-931. 
Poulin, P., and Krishnan, K. 1995a. An algorithm for predicting tissue:blood partition coefficients of organic chemicals from n-octanol:water partition coefficient data. J. Toxicol. Environ. Health A 46:117-129.

Poulin, P., and Krishnan, K. 1995b. A biologically-based algorithm for predicting human tissue:blood partition coefficients of organic chemicals. Hum. Exp. Toxicol. 14:273-280.

Poulin, P., and Krishnan, K. 1996. A mechanistic algorithm for predicting blood:air partition coefficients of organic chemicals with the consideration of reversible binding in hemoglobin. Toxicol. Appl. Pharmacol. 136:131-137.

Renzi, F., and Waud, B. E. 1977. Partition coefficients of volatile anesthetics in Krebs' solution. Anesthesiology 47:62-63.

Sato, A., and Nakajima, T. 1979a. Partition coefficients of some aromatic hydrocarbons and ketones in water, blood and oil. Br. J. Ind. Med. 36:231-234.

Sato, A., and Nakajima, T. 1979b. A structure-activity relationship of some chlorinated hydrocarbons Arch. Environ. Health 34:69-75.

Steward, A., Allott, P. R., Cowles, A. L., and Mapelson, W. W. 1973. Solubility coefficients for inhaled anaesthetics for water, oil and biological media. Br. J. Anaesth. 45:282-293.

Warren, D. A., Reigle, T. G., Muralidhara, S., and Dallas, C. E. 1998. Schedule-controlled operant behavior of rats during 1,1,1-trichloroethane inhalation: Relationship to blood and brain solvent concentrations. Neurotoxicol. Teratol. 20:143-153.

White, R. F., and Proctor, S. P. 1997. Solvents and neurotoxicity. Lancet 349:1239-1243. 